\title{
The Concept of Cognitive Vitality: Analysis and Clinical and Research Implications
}

\author{
Boniface Harerimana ${ }^{1 *}$, Michael Borrie ${ }^{2}$, Julie Walsh ${ }^{3}$, Jennifer Fogarty ${ }^{4}$ and Cheryl Forchuk ${ }^{5}$ \\ ${ }^{1}$ School of Nursing Arthur and Labatt, Western University Ontario, Canada \\ ${ }^{2}$ Department of Medicine \& Dentistry, University of Western Ontario, Canada \\ ${ }^{3}$ Lawson Health Research, Parkwood Institute Research, Canada \\ ${ }^{4}$ Department of Medicine \& Dentistry, University of Western Ontario, Canada \\ ${ }^{5}$ Arthur Labatt Family School of Nursing \& Schulich Medicine \& Dentistry, Parkwood Institute Research \& University of Western Ontario, Canada
}

*Corresponding author: Boniface Harerimana, Mental Health Nursing Research Alliance, Lawson Health Research Institute, Parkwood Institute - Main Building, 550 Wellington Road, Suite B3-110, London, P.0. Box 5777, STN B, N6A 4V2, Canada.

To Cite This Article: Boniface Harerimana, The Concept of Cognitive Vitality: Analysis and Clinical and Research Implications. 2020 - 10(2). AJBSR. MS.ID.001487. DOI: 10.34297/AJBSR.2020.10.001487.

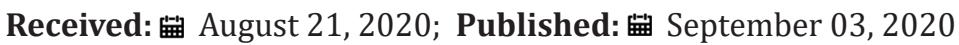

\begin{abstract}
Age-related cognitive decline poses significant individual and societal economic burdens. Substantial research has demonstrated that enhancing cognitive vitality can delay age-related cognitive decline. However, scholarship has inconstantly used cognitive vitality and provided far less information about its traits and pragmatic indicators. The present scholarly work analyzed the concept of cognitive vitality using the [1] framework to propose clear definitions, defining attributes, antecedents, and empirical references of this concept. In the end, a model explaining mechanisms underpinning the concept and a new definition was constructed.

The new definition proposes that cognitive vitality can be referred as an individual's ability to successfully use their energy to adapt to cognitive changes and maintain an optimum level of cognitive functioning, life satisfaction, and independent living. The definition and subsequent model will make cognitive vitality more unified, meaningful in a global sense, and expand the scope of concept use while adding depth and new variables to the term. Furthermore, this paper adds to existing literature insights that are valuable for interpreting clinical data and guiding further studies related to the concept.
\end{abstract}

\section{Introduction}

Recent studies suggest that 2.1 billion of the world population will be aged over 65 years old by 2050 [2]. An increase in the elderly population is accompanied by individual and societal economic burdens associated with age-related cognitive decline [3]. These burdens have fuelled efforts to explore mechanisms to maintain and enhance cognitive vitality, especially among older adults and people with brain disorders, such as dementia [4]. While research has established interactions between neurobiological and environmental factors for cognitive vitality, the literature has inconsistencies in defining this concept, and little is known about its attributes and objective empirical indicators.
The concept of cognitive vitality has been elusively operationalized in studies that have explored individual determinants of health conditions [5-7] and lifestyle [8,9] that influence and sustain cognitive vitality. The inconsistency of concept was also exemplified by the lack of definition and stable empirical indicators. For example, several studies [10-13] had used cognitive vitality as a research variable; however, their empirical definitions differed widely. Faced with this inconsistent use of the concept of cognitive vitality, researchers and clinician alike may find it difficult to reach an accurate and harmonious interpretation of information collected from clients. 
Besides the inconsistency in defining attributes, cognitive vitality as a concept varies across disciplines. For instance, in gerontology, cognitive vitality is used to denote the maintenance of cognitive functioning that enables the elderly to adapt to brain changes with aging and to sustain their well-being within their living environment [14-16]. However, in neurobiology, it is used to refer to either cognitive health or an absence of cognitive decline, i.e. preservation of cognitive functions and ability to adapt to changing and challenging conditions [5,7,17-20]. In view of these different conceptualizations of the concept of cognitive vitality, there is a need for clear definitions of this concept. Therefore, the present paper reports a concept analysis with the purpose of closing this gap by proposing clear definitions, defining attributes, antecedents, and empirical references of this concept.

\section{Methods}

This conceptual analysis followed a framework developed by [1] framework has demonstrated potentials for concept analyses in health sciences. The framework proposes six essential stages, which comprise identifying a concept; defining the purpose of analysis; identifying cross-discipline definitions; determining antecedents and defining attributes; defining empirical referents; and consequences of a concept under analysis.

\section{Identification of Sources of Data}

To retrieve data, a systematic search through electronic databases, including Ovid MEDLINE, Psych Info, Embase, ProQuest, CINHAL, and Cochrane Library was conducted. Additional scholarly reports were retrieved by scanning references of identified articles and websites. The following keywords were used to search through electronic databases: cognitive vitality, cognitive ability, cognition, cognitive decline, cognitive health, and cognitive wellbeing. After identification of articles and other scholarly reports (see Figure 1), data corresponding to definitions or synonyms/antonyms, defining attributes, antecedents, empirical referents, and consequences of cognitive vitality were extracted and managed using a matrix. However, due to language limitations, this concept analysis included only English and French reports. The following sections present the results of the analysis (Figure 1).

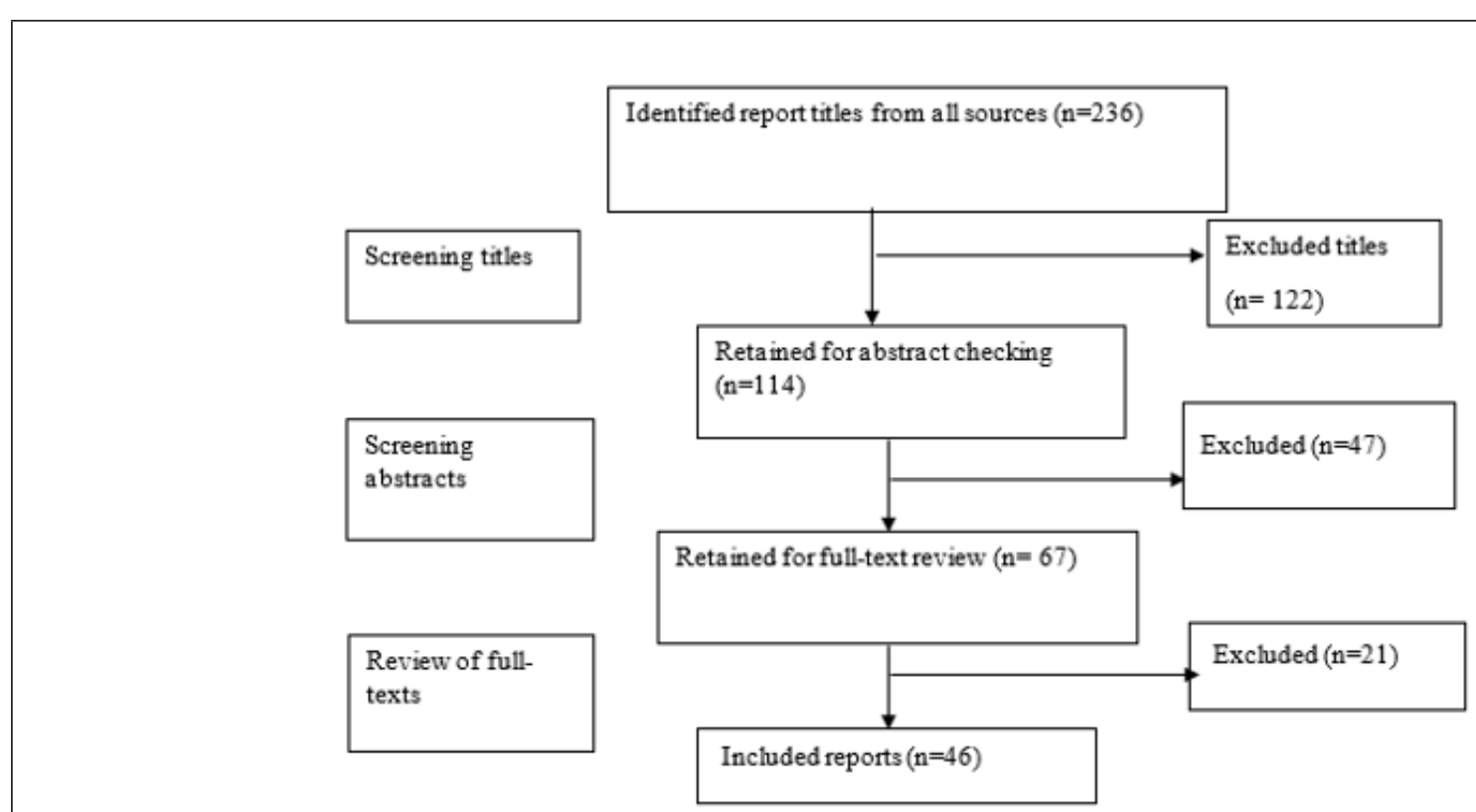

Figure 1: Identification and selection of data sources.

\section{Definitions}

\section{Synonym terms}

In gerontology, cognitive ability and cognitive efficiency are used as synonymous terms of cognitive vitality [21,22]; whereas epidemiological studies sometimes use intellectual vitality [23]. Cognitive vitality is also symbolized as successful aging or aging well [24-26], which implies the absence of major physical disability and cognitive impairment until later age [17]. Another synonymous term for cognitive vitality is cognitive health stemming from geriatric and Alzheimer research [27]. Terms such as mental abilities, daily functioning, and independent living are used to describe cognitive vitality among older adults [28]. Furthermore, in older adults with neurodegenerative disorders, cognitive vitality and survival ability are used interchangeably to denote one's abilities to perform instrumental activities of daily living and cognitive functions regardless of the presence of neurodegenerative disease [29]. In some stances, successful cognitive aging and resiliency, are umbrella terms under which cognitive vitality falls [30]. 


\section{Definitions}

The concept of cognitive vitality has two distinct but complementary components "cognitive and vitality", whose definitions vary depending on the field of use. Vitality as a word may be traced back to the late 16th century from the Latin word "vitalitas", which is also from "vitalis". The Oxford Dictionary [31] defines vitality as the state of being strong and active; and having the energy or the power giving continuance of life, which is present in all living things (e.g. the vitality of seeds). In Stern [32] perspectives, vitality contours do not necessarily relate to the content of an experienced event or act; instead, they reflect the manner in which the event/ act is experienced and the feelings that direct the event or act. Building on the preceding perspectives, vitality can be understood as intrinsic and temporal feelings that underlie one's appreciation of an experienced event or act, which in this case is one's cognitive function. In support of the preceding perspectives, George Klein (1976) in [33] defined vitality as "personal feelings of pleasure in experiencing the self as an effective agent of change (which) resides in the perception that through one's interference one has changed and can change the course of events once set in motion" (p.367). Vitality constitutes an ingredient that comes to govern the manner by which action will be executed "the how"; subsequently, it acts as a regulator for the dynamics of human responses to intrinsic and extrinsic stimuli [34]. Vitality, as organismic well-being, interacts with both psychological and somatic factors to impact the inner strength available to the self [35].

On the other hand, the cognitive component of this concept is defined by [31] as an adjective denoting something related to cognition, a name originating in the 16th century from the medieval Latin word "cognitive", deriving from another word "cognit" that signifies known. However, [30] warned scholars of surrogate terms that are often confused with cognitive vitality. The first of these terms is cognitive functioning, which denotes performancebased indicators of cognitive ability or skill [30]. Indicators of cognitive functioning include perceptual speed, episodic memory, incidental memory, and semantic memory [6]. A second term is that of cognitive aging, which refers to documented changes in cognitive functioning that occur throughout adult development and aging [30]. The third is cognitive health that, in a more global term, describes the spectrum of aggregate cognitive functioning varying from absence of impairment to mild cognitive impairment and more severe impairment, such as dementing disorders [30]. However, there is no one universal definition for cognitive vitality [23].

In epidemiological studies, cognitive vitality is often referred to as maintenance of intellectual vitality [23]. This implies the preservation of an optimal level of cognitive performance and brain restructuring activities that have been associated with an individual's response to exposure to a stimulating social environment [23]. Another definition from aging research done by [27] used cognitive health, a synonymous term of cognitive vitality [27] asserted that cognitive health is not merely the absence of disease, but rather a personal achievement and enrichment of multidimensional cognitive structures that allow an individual to sustain social connectedness, an ongoing sense of purpose, along with the ability to function independently, facilitate functional recovery from illness or injury, and to cope with residual functional deficits (p.13). Additionally, cognitive vitality reflects extended cognitive health, which capitalizes on one's cognitive skills and resources to maintain successful cognitive functioning and adaptation to daily life conditions [25]. This is especially important, among people who are faced with debilitating conditions, such as stroke, acquired brain injury, dementia and major depressive disorder [36]. Cognitive vitality also represents the retention of high cognitive functions and maintenance of one's intellect despite old age [5].

A recent definition introduced by [30] proposed that cognitive vitality expands beyond experiencing dementing disorders, and as such its definition incorporates both cognitive functioning, other skills, and disposition, which are applied for successful adaptation to an individual's unique everyday environment. This definition embraces [37] perspective, which proposes that cognitive vitality can represent a compensatory process that uses preserved and improved cognitive resources (e.g., knowledge-based abilities) to keep cognitive and brain functions at a high level of efficiency despite an age-related cognitive decline in other domains, including psychomotor performance. Neuroscientific evidence implicitly supports that cognitive vitality relates to enhanced cognitive performance, brain function and structures in later adulthood [4]. Neuropsychologists have further underscored that cognitive vitality can be referred to as the maintenance of cognitive health that enables older people to enjoy an independent/autonomous life as long as possible regardless of progressive age-related cognitive decline [24]. From health promotion perspectives, cognitive vitality is an accumulation of possibilities of staying mentally or intellectually sharp into old age through a sustained by cognitive reserve, acquired knowledge, and avoiding brain insults [15]. As the summary of definitions shows (see Table 1), a cognitively vital individual remains socially engaged, productive, and can function independently both at a physical and cognitive level [38] (Table 1).

\section{Defining Attributes of Cognitive Vitality}

Cognitive vitality is defined by a variety of cognitive and vitality attributes. The concept analysis results found that the current literature linked attributes in Table 2 to cognitive vitality.

\section{Antecedents}

Developing and maintaining cognitive vitality relies on a combination of internal and external antecedents (i.e., precursors). 
Internal precursors that have been consistently linked to cognitive vitality include genetic heritability, such as being born in a family of centenarians [23]. Other internal precursors include protecting the brain from insults or harms associated with smoking and heavy alcohol use as well as [4] properly manage medical comorbidities such as hypertension, diabetes, and hypercholesterolemia [25]. External precursors include living an engaged lifestyle involving rich novel experiences which stimulate complex cognitive processes, such as decision making, creativity, evaluation of ideas, and competition [28,39]. Additionally, cognitive vitality has been linked to external precursors, such as maintenance of social connectedness and social activities; healthy eating; and a higher level of education and professional occupation [23].

There are several interventions which can bolster cognitive vitality among older adulthood or alleviate old-related cognitive decline [40]. Interventions which include intellectually stimulating activities; for example, riddles, logic games or memory tasks, sustain cognitive vitality in the geriatric population [18]. Additionally, interventions which maintain cognitive vitality capitalize on traditional computerized cognitive rehabilitation programs (e.g., repeated drill and practice exercises involving memory, attention, and executive functions) and motivational enhancing and rehabilitation techniques $[6,7]$ indicated that cognitive vitality benefits from engaging in continuous learning from simple to more difficult skills, such as digital photography, e.g., basic camera operations and progress to using high-level editing software and photography techniques. Alternatively, individuals may undertake Table 1: Summary of definitions.

\begin{tabular}{|c|c|c|}
\hline Concepts & References & Definitions \\
\hline \multirow[t]{3}{*}{ Vitality } & The Oxford Dictionary [31] & $\begin{array}{c}\text { The state of being strong and active; and having the energy or the power giving contin- } \\
\text { uance of life. }\end{array}$ \\
\hline & Ammaniti and Ferrari [33] & $\begin{array}{l}\text { Personal feelings of pleasure in experiencing the self as an effective agent of change and } \\
\text { capable of changing the course of events }\end{array}$ \\
\hline & Di Cesare, De Stefani, Gentilucci et al. [34] & A regulator for the dynamics of human responses to intrinsic and extrinsic stimuli. \\
\hline \multirow[t]{6}{*}{$\begin{array}{l}\text { Cognitive } \\
\text { vitality }\end{array}$} & Belley, Parisien, Nour et al. [23] & $\begin{array}{c}\text { The preservation of an optimal level of cognitive performance and brain restructuring } \\
\text { activities. }\end{array}$ \\
\hline & Margrett et al. [30] & $\begin{array}{c}\text { Successful adaptation to an individual's unique everyday environment, such as an expe- } \\
\text { rience of dementing disorders. }\end{array}$ \\
\hline & Minicuci et al. [25] & $\begin{array}{l}\text { An extended cognitive health, which leads to maintaining successful cognitive function- } \\
\text { ing and adaptation to daily life conditions. }\end{array}$ \\
\hline & Kramer, Willis [37] & $\begin{array}{l}\text { A compensatory process for keeping cognitive and brain functions at a high level of } \\
\text { efficiency despite an age-related cognitive decline in other domains. }\end{array}$ \\
\hline & Kovacich et al. [16] & An accumulation of possibilities of staying mentally or intellectually sharp into old age. \\
\hline & Cassarino et al. [24] & $\begin{array}{c}\text { The maintenance of cognitive health that enables older people to enjoy an independent } \\
\text { /autonomous life as long as possible regardless of progressive age-related cognitive } \\
\text { decline. }\end{array}$ \\
\hline
\end{tabular}

Source: Data extracted from reports included in this concept analysis.

Table 2: Key attributes of cognitive vitality.

\begin{tabular}{|c|c|}
\hline References & Defining Attributes \\
\hline Fry, Keyes [21] & The ability to achieve new learning, continued growth, and enhanced life satisfaction. \\
\hline
\end{tabular}

quilting lessons (design of complex abstract patterns), or a combination of both quilting and photography [9]. Interventions intended to promote cognitive vitality may also include combining motivational teaching and rehabilitation techniques into a highly engaging program that emphasizes enjoyment, intrinsic motivation, and active participation, while also engaging in a more traditional computer-based memory training program [41].

Cognitive vitality can benefit from different lifestyle choices, including participating in physical activities (PAs) in middleadulthood which increase cerebral blood and development of new capillaries in the hippocampus, cerebellum and motor cortex, and enhanced brain structures [8]. Research has linked these changes in brain structures and vascularization to increased production of neurotrophic molecules, such as brain-derived neurotrophic factors (BDNF), and a series of molecular and cellular cascades [4]. A review of literature supported that PAs induce neuroplasticity substrates, neurotrophic signaling, neurogenesis, stress response, and antioxidant defense, in the brain whereas cognitive engagement enhances brain and cognitive reserve [15]. The review indicated that PAs increase neurotrophic signaling which in turn stimulates BDNF that is crucial for maintenance, growth, and synaptic plasticity of neurons, an essential mechanism for healthy emotions and cognition. PAs not only increase adult neurogenesis, synaptic plasticity, learning in the dentate gyrus of the hippocampus, but also alleviate chronic inflammation a condition associated with cognitive impairment, mood disorders, cardiovascular diseases, and neurodegenerative disorders [14] (Table 2). 


\begin{tabular}{|c|c|}
\hline Gow et al. [45] & $\begin{array}{c}\text { Enhanced cognition, regardless of the person's age, and positive subjective well-being, such as one's happi- } \\
\text { ness with life. }\end{array}$ \\
\hline $\begin{array}{l}\text { Stine-Morrow, Parisi, Morrow, Park. } \\
\text { [39] }\end{array}$ & Lifelong abilities to augment and maintaining cognitive functions. \\
\hline Ball et al. [28]; Gooding et al. [7] & $\begin{array}{l}\text { Cognitive processes including memory performance speed for information processing and reasoning abili- } \\
\text { ties. }\end{array}$ \\
\hline Gutmanis, Lee Teasell. [36] & $\begin{array}{c}\text { Sufficient cognitive functioning that enables a person to: perform tasks required by their age and condi- } \\
\text { tions; experience no or minimal physical or mental discomfort, and some sense of contentment; experience } \\
\text { well-being despite reduced cognitive function; manifest social abilities and initiative of functioning beyond } \\
\text { what could be expected by their level of cognitive functioning alone; and can navigate vitality in social and } \\
\text { other activities. }\end{array}$ \\
\hline Troyer [39] & The ability to minimize memory mistakes, such as forgetting people's names and delivering a message. \\
\hline Minicuci et al. [25] & Maintaining successful cognitive functioning and adaptation to daily life conditions. \\
\hline Ryan, Frederick. [35] & $\begin{array}{l}\text { Vitality is defined by a positive feeling of aliveness and energy, adaptation energy which people use when } \\
\text { facing environmental and disease stressors; and thus, it represents a principal factor in resilience. }\end{array}$ \\
\hline
\end{tabular}

Source: Data extracted from reports included in this concept analysis

A review of gerontology evidence by [16] demonstrated that the importance of lifestyle choices in protecting cognitive vitality [16] found diet rich in E vitamins and mental exercise, such as that keeps the mind active exert a protective effect on cognitive vitality. In the same vein, to promote cognitive vitality, various resources advocate for a lifestyle that sustains healthy functionality of the body systems, including cardiopulmonary, musculoskeletal, sense organs, psychological, mental functions [42], and healthy eating, such as a Mediterranean diet $[17,18,22]$.

\section{Empirical Referents}

Empirical referents are measurable domains or categories of actual phenomena that by their existence or presence indicate the occurrence of the concept itself [1]. The concept of cognitive vitality has empirical referents related to cognitive functions, including processing speed, working memory, inductive reasoning, everyday problem solving, visual-spatial processing, and divergent thinking [12,39]. Other empirical referents related cognitive functions are that of memory performance, ability of correctly identifying information in familiar everyday stimuli, and information processing focused on the speed with which a person can identify specific information (e.g. telephone numbers, names of items in an overcrowded grocery store and counting specified amounts of change) [28,40]. The American Bar Association Commission on Law and Aging (ABACLA) and American Psychological Association (APA) [43] have embraced the preceding referents, and proposed dimensions related to: attention, specifically concentration on a stimulus over brief time periods; three types of memory, working memory, recent memory and learning and long-term memory that consists of remembering information from the past; language abilities comprised of expressing one's self in words and writing, expressing one's preferences, and understanding written, spoken, and visual language; maintenance of mathematics skills; abilities to have insight.
As for reasoning, the ABACLA and APA [43] proposed pragmatic ways of assessment, which consists of exercising logical reasoning about outcomes and comparing two choices, along with visualspatial reasoning which involves perception and visual problemsolving. Similarly, executive functions of a person with cognitive vitality preserve abilities to make plans and logic judgement and to inhibit inappropriate responses [43]. In addition, there are numerous empirical referents of the vitality component of this concept. Within the aging population experiencing dementia, variables of vitality include waking pattern, communication, feeding, getting on and off the toilet, rehabilitation and other activities $[29,44]$. These variables interact with subjective cognitive dimensions, such as confidence in and feeling control over cognitive abilities, subjective memory functioning, and attention in daily life [39].

Taken together, there is no single measure for the concept of cognitive vitality. As such, cognitive and vitality components are measured independently. The following are examples of five essential empirical domains: physiological and metabolic health: cardiovascular function, lung function, glucose, and body compositions; physical capability: strength, endurance, locomotion, dexterity, and balance; cognitive function: processing speed, episodic memory, executive function; psychological well-being: positive and negative affect, life satisfaction, quality of life, mental health, and resilience; social well-being: social network, social functioning, perceived emotional/social support, sense of purpose $(26,38)$. A list of examples of measures for empirical referents of cognitive vitality is presented in Appendix 1.

\section{Consequences}

\section{Cognitive vitality acts as an enabler for continued growth and healthy longevity}

In aging people, cognitive vitality can serve as an enabler for maintaining a complementary focus on psychological strengths, 
positive emotions, and regenerative capacities to achieve continued growth and healthy longevity [21]. At a physiological level, being cognitively vital facilitates cognition through increased neural efficiency and neuroprotective, an essential element to maintaining a healthy brain into late adulthood [9].

\section{Cognitive vitality improves quality of life and satisfaction throughout the aging process}

Individuals with cognitive vitality have an improved quality of life, i.e. happiness and satisfaction with one's aging life [45] Cognitive vitality not only results in improved longevity, but also facilitates quality of life through the person's improved resistance to dementia, and enhanced cognitive flexibility [9,39]. Research has indicated that activities that improve older adults' confidence and feelings of control over cognitive abilities can enhance their cognitive health and overall health outcomes [39].

\section{Cognitive vitality sustains daily functioning and independent living until later life}

Cognitive vitality leads to successful aging through the preservation of cognitive functions [17] in the form of attention and concentration necessary for an independent living until an older age $[22,28]$ combined cognitive vitality with health outcomes, such as mental abilities, daily functioning, and independent living

\section{Conclusion and Implications}

among aging people. In a study exploring perspectives of 91+ years old participants, they expressed that cognitively vital individuals can keep one's own home and live there as long as possible, living independently, preferably in their own homes rather than being institutionalized [45].

\section{Cognitive vitality, a catalyst for a compensatory mechanism}

In cognitively vital individuals, some domain-specific learned skills can be maintained at a high level of proficiency over the 70s and be applied to compensate cognitive decline affecting other domains functions, e.g., deficits in psychomotor performance [37]. As such, cognitive vitality facilitates individuals faced with the reduced or cognitive decline to apply preserved, develop and find novel skills that compensate their deficits and protect against further cognitive decline [36]. As a result, a cognitively vital individual adapts to demands required by new changes in time and their environment, as well as physical health or affective conditions. Despite the occurrence of declines in specific cognitive functions, the brain remains capable of adapting to stimuli through cognitive functions that increase with age [5]. Therefore, this adaptation process compensates for functions that may be impaired by both normal cognitive aging and diseases that cause dementia, specifically Alzheimer disease and vascular dementia [4].

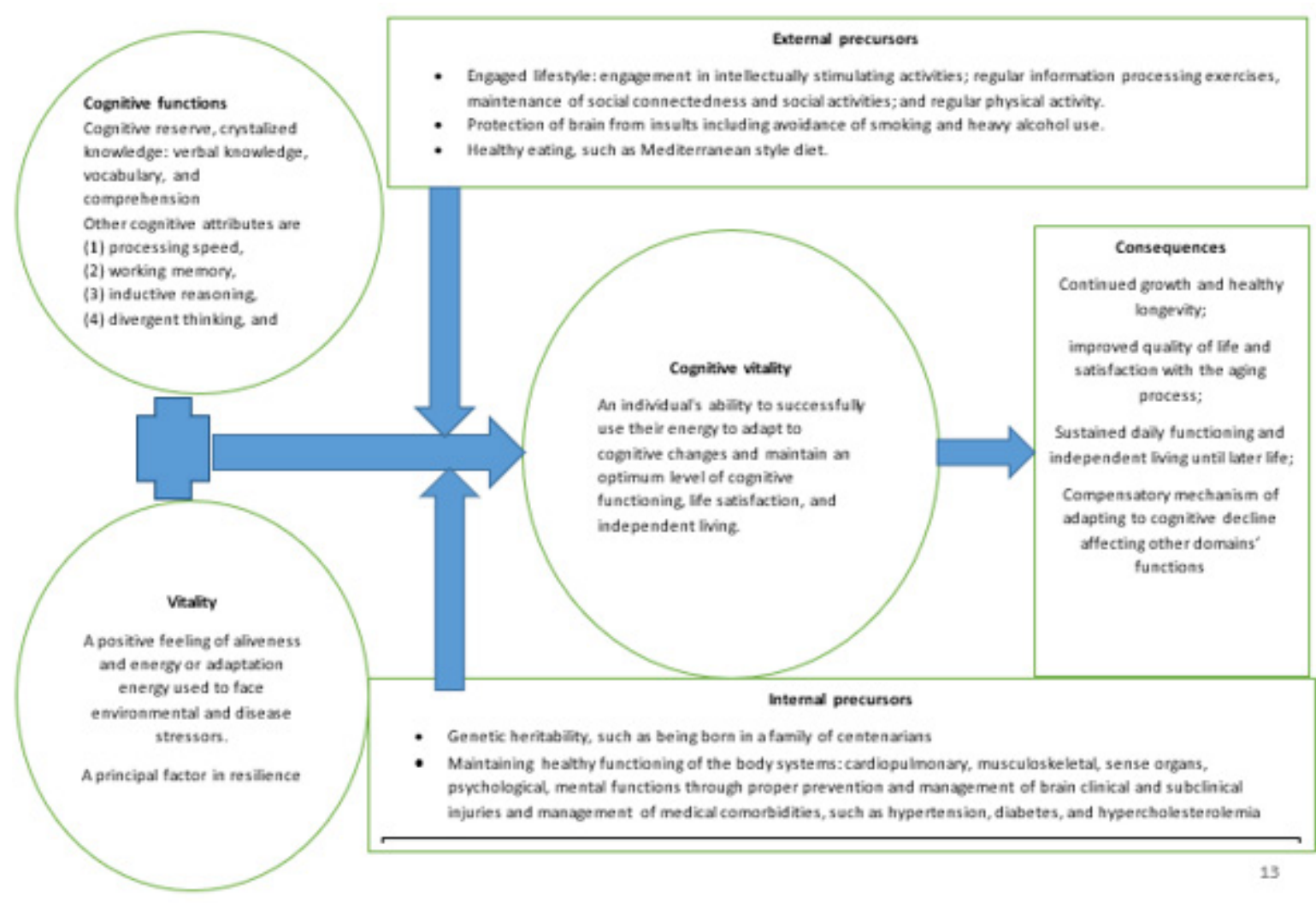

Figure 2: A model of interactions between pressors and components of cognitive vitality. 
This concept analysis evaluated various definitions, synonyms, defining attributes, antecedents, empirical references, and consequences of the concept of cognitive vitality. The concept analysis proposed a new definition and a model (Figure 2) that articulates interactions between these components of cognitive vitality. The new definition proposes that cognitive vitality can be understood an individual's ability to successfully use their energy to adapt to cognitive changes and maintain an optimum level of cognitive functioning, life satisfaction, and independent living. Furthermore, cognitive vitality acts as a compensatory mechanism for adapting to cognitive decline that affects other domains' functions during the aging process. It is expected that the new definition and subsequent model will make cognitive vitality more unified, meaningful in a global sense, and expand the scope of concept use while adding depth and new variables to the term. The current body of knowledge espoused by this analysis will enhance the effective, appropriate and broad use and application of the concept in the fields of psychiatry, neuroscience, gerontology, psychology, sociology and nursing care of the elderly in both hospital and home settings. New tools that may be developed based on the new definition are likely to impact positively on gerontology research by directing research activities that may yield optimum outcomes.

\section{Conflicts of Interest}

The authors declare no conflict of interest.

\section{Acknowledgments}

The authors would like to thank Parkwood Institute Research for financially supporting this work through 2018 Doctoral and Post-Doctoral Summer Project Scholarship. The authors also express gratitude to Dr. Bizoza Rutakayire, Senior Psychiatrist Consultant and Lecturer at University of Rwanda, for accepting to revise and validate the interpretations of data extracted from French report included in this concept analysis.

\section{Funding}

This work was supported by the Parkwood Research Institute through Doctoral and Postdoctoral Trainee Summer Project 2018.

\section{References}

1. Walker LO, Avant KC (2005) Strategies for theory construction in nursing. Higher Education, Pearson.

2. Shah H, Albanese E, Duggan C, Rudan I, Langa KM, et al. (2016) Research priorities to reduce the global burden of dementia by 2025. The Lancet Neurology 15(12): 1285-1294.

3. Population Division. World population ageing 2019. Department of Economic and Social Affairs, New York, USA.

4. Kramer AF, Erickson KI (2007) Capitalizing on cortical plasticity: influence of physical activity on cognition and brain function. Trends in cognitive sciences 11(8): 342-348.
5. Fillit HM, Butler RN, O'connell AW, Albert MS, Birren JE, et al. (2002) Editors. Achieving and maintaining cognitive vitality with aging. Mayo Clinic Proceedings 77(7): 681-696.

6. Mac Donald SW, Hundza S, Love JA, De Carlo CA, Halliday DW, et al. (2017) Concurrent indicators of gait velocity and variability are associated with 25-year cognitive change: a retrospective longitudinal investigation. Frontiers in aging neuroscience 9: 17.

7. Gooding AL, Choi J, Fiszdon JM, Wilkins K, Kirwin PD, et al. (2016) Comparing three methods of computerized cognitive training for older adults with subclinical cognitive decline. Neuropsychol Rehabil 26(5-6): 810-821.

8. Kramer AF, Colcombe S (2018) Fitness effects on the cognitive function of older adults: A meta-analytic study-revisited. Perspect Psychol Sci 13(2): 213-217.

9. Mc Donough IM, Haber S, Bischof GN, Park DC (2015) The Synapse Project: engagement in mentally challenging activities enhances neural efficiency. Restor Neurol Neurosci 33(6): 865-882.

10. Kaup AR, Mirzakhanian H, Jeste DV, Eyler LT (2011) A review of the brain structure correlates of successful cognitive aging. J Neuropsychiatry Clin Neurosci 23(1): 6-15.

11. Kawabata M, Yamazaki F, Guo DW, Chatzisarantis NLD (2017) Advancement of the Subjective Vitality Scale: examination of alternative measurement models for Japanese and Singaporeans. Scand J Med Sci Sports 27(12): 1793-1800.

12. Fayad YI, Kazarian SS (2013) Subjective Vitality of Lebanese Adults in Lebanon: Validation of the Arabic Version of the Subjective Vitality Scale. Social Indicators Research 114(2): 465-478.

13. Hendrie HC, Albert MS, Butters MA, Gao S, Knopman DS, et al. (2006) The NIH cognitive and emotional health project: report of the critical evaluation study committee. Alzheimers Dement 2(1): 12-32.

14. Colcombe S, Kramer AF (2003) Fitness effects on the cognitive function of older adults: a meta-analytic study. Psychol Sci 14(2): 125-130.

15. Phillips C (2017) Lifestyle modulators of neuroplasticity: How physical activity, mental engagement, and diet promote cognitive health during aging. Neural plasticity.

16. Kovacich J, Garrett R, Forti EM (2006) New learning programs in cognitive vitality, Alzheimer's Disease, and related dementias. Gerontology \& Geriatrics Education 26(4): 47-61.

17. Gorelick PB (2005) William M Feinberg Lecture: Cognitive vitality and the role of stroke and cardiovascular disease risk factors. Stroke 36(4): 875-879.

18. Gorelick PB (2018) Prevention of cognitive impairment: scientific guidance and windows of opportunity. J Neurochem 144(5): 609-616.

19. Laforest S, Lorthios-Guilledroit A, Nour K, Parisien M, Fournier M, et al. (2017) Attitudes and lifestyle changes following Jog your Mind: results from a multi-factorial community-based program promoting cognitive vitality among seniors. Health Education Research. 32(2): 184-196.

20. Watson NL, Sutton-Tyrrell K, Rosano C, Boudreau RM, Hardy SE, et al. (2011) Arterial stiffness and cognitive decline in well-functioning older adults. J Gerontol ABiol Sci Med Sci 66(12): 1336-1342.

21. Fry PS, Keyes CL (2010) New frontiers in resilient aging: Life-strengths and well-being in late life: Cambridge university press. England.

22. Cassarino M, Setti A (2015) Environment as 'Brain Training': A review of geographical and physical environmental influences on cognitive ageing. Ageing Res Rev 23(Pt B): 167-182.

23. Belley A-M, Parisien M, Nour K, Bier N, Ferland G, et al. (2013) Perspective écologique sur les déterminants de la vitalité cognitive des 
aînés. Canadian Journal on Aging/La Revue canadienne du vieillissement 32(3): 240-249.

24. Cassarino M, O'sullivan V, Kenny RA, Setti A (2016) Environment and cognitive aging: A cross-sectional study of place of residence and cognitive performance in the Irish longitudinal study on aging. Neuropsychology 30(5): 543-557.

25. Minicuci N, Marzari C, Maggi S, Noale M, Senesi A, et al. (2005) Predictors of transitions in vitality: the Italian longitudinal study on aging. ] Gerontol A Biol Sci Med Sci 60(5): 566-573.

26. Anton SD, Woods AJ, Ashizawa T, Barb D, Buford TW, et al. (2015) Successful aging: advancing the science of physical independence in older adults. Ageing research reviews 24(Pt B): 304-327.

27. Hendrie HC, Albert MS, Butters MA, Gao S, Knopman DS, et al. (2006) The NIH cognitive and emotional health project: report of the critical evaluation study committee. Alzheimers Dement 2(1): 12-32.

28. Ball K, Berch DB, Helmers KF, Jobe JB, Leveck MD, et al. (2002) Effects of cognitive training interventions with older adults: a randomized controlled trial. JAMA 288(18): 2271-2281.

29. Toba K, Nakai R, Akishita M, Iijima S, Nishinaga M, et al. (2002) Vitality Index as a useful tool to assess elderly with dementia. Geriatrics \& Gerontology International 2(1): 23-29.

30. Margrett JA, Mast BT, Isales MC, Poon LW, Mansfield JC, et al. (2011) Cognitive functioning and vitality among the oldest old: implications for well-being. USA.

31. (2019) The Oxford Dictionary of English, USA.

32. Stern DN (1999) Vitality contours: The temporal contour of feelings as a basic unit for constructing the infant's social experience. Early social cognition: Understanding others in the first months of life p. 67-80.

33. Ammaniti M, Ferrari P (2013) Vitality affects in Daniel Stern's thinking-A psychological and neurobiological perspective. Infant Mental Health Journal 34(5): 367-375.

34. Di Cesare G, De Stefani E, Gentilucci M, De Marco D (2017) Vitality forms expressed by others modulate our own motor response: a kinematic study. Frontiers in human neuroscience 11: 565
35. Ryan RM, Frederick C (1997) On energy, personality, and health: Subjective vitality as a dynamic reflection of well-being. Journal of personality 65(3): 529-565.

36. Gutmanis, I Lee T, Teasell R (2013) Strategies that promote cognitive vitality in the presence of cognitive impairment: Stroke, acquired brain injury, dementia and major depressive disorder, London.

37. Kramer AF, Willis SL (2002) Enhancing the cognitive vitality of older adults. Current directions in psychological science 11(5): 173-177.

38. Lara J, Godfrey A, Evans E, Heaven B, Brown LJ, et al. (2013) Towards measurement of the Healthy Ageing Phenotype in lifestyle-based intervention studies. Maturitas 76(2): 189-199.

39. Stine-Morrow EA, Parisi JM, Morrow DG, Park DC (2008) The effects of an engaged lifestyle on cognitive vitality: a field experiment. Psychol Aging 23(4):778-786.

40. Park DC, Goh J (2009) Successful aging. Handbook of Adolescent Psychology.

41. Gooding AL (2014) The relationship between baseline executive functioning and treatment response for individuals with mild cognitive impairment receiving cognitive rehabilitation, Fordham University, USA.

42. Freude G, Jakob O, Martus P, Rose U, Seibt R, et al. (2009) Predictors of the discrepancy between calendar and biological age. Occup Med (Lond) 60(1): 21-28.

43. Nosraty L, Jylhä M, Raittila T, Lumme-Sandt K (2015) Perceptions by the oldest old of successful aging, Vitality 90+ Study. J Aging Stud 32: 50-58.

44. Sonohara K, Kozaki K, Akishita M, Nagai K, Hasegawa H, et al. (2008) White matter lesions as a feature of cognitive impairment, low vitality and other symptoms of geriatric syndrome in the elderly. Geriatr Gerontol Int 8(2): 93-100.

45. Gow AJ, Whiteman MC, Pattie A, Whalley L, Starr J, et al. (2005) Lifetime intellectual function and satisfaction with life in old age: longitudinal cohort study. Bmj 331(7509): 141-142. 